\title{
Detecting scour and liquefaction using OBS sensors
}

\author{
H. An \& L. Cheng \\ School of Civil, Environmental and Mining Engineering, University of Western Australia, Australia
}

M. Zhao

School of Computing, Engineering and Mathematics, Western Sydney University, Australia

G. Tang

Stake Key Laboratory of Coastal and Offshore Engineering, Dalian University of Technology, China

\section{S. Draper}

School of Civil, Environmental and Mining Engineering and Centre of Offshore Foundation System, University of Western Australia, Australia

\begin{abstract}
This work examined the performance of Optical Back-Scatter (OBS) sensors for detecting sediment movement around a model subsea structure. Three types of tests were conducted using a circular cylinder model equipped with 16 OBS sensors. The sensor recorded a dramatic reduction in back scatter when it became unburied (due to sediment movement) and was exposed to clear water. Based on this feature, the sensors were used to investigate the scour processes around a model pile, and the spanwise scour rate of a partially buried model pipeline. The test results agree well with existing knowledge. When the sensors were fully buried in sand, it was also observed that the sensor readings fluctuate noticeably when sand particles move local to the sensors. Based on this feature, the OBS sensors were used to detect sediment movement induced by seabed liquefaction. Through the tests presented in this paper, it has been demonstrated that the sensor can be used as a new device to detect local scour and liquefaction in laboratory tests.
\end{abstract}

\section{INTRODUCTION}

\subsection{Background}

Sediment movement on a seabed mainly happens in two ways. Firstly, when the flow shear stress acting on sediment particle exceeds a critical value, the sand particles will become unstable and are transported away by the flow. This is the so-called sediment transport phenomenon. Secondly, sediment on a seabed may liquefy due to wave/earthquake induced pore-pressure build-up when the effective shear stress in the sediment layer approaches to zero. Both sediment transport and seabed 1 iquefaction can lead to instabilities of subsea structures installed on seabed. Due to this reason, a vast amount of physical modelling and field monitoring work has been carried out to investigate the phenomena.

\subsection{Review}

Due to the complex physics involved in sediment transport processes around structures, the research about local scour around structures is mainly through field observations and laboratory model testing. A variety of sensors and devices have been developed and applied for laboratory testing and field measurements. The devices used in the field mainly employ three different types of signals, including (i) acoustic signals, (ii) electro-magnetic signals, and (iii) electrical conductivity signals. For laboratory testing, besides the above mentioned devices, laser signals may be used under clear water conditions. A brief literature review will be given to summarize the working principle and features of the scour detecting devices.

Electrical conductivity devices can detect the differences in the electrical conductivity of various media by measuring the electrical current between two probes (Cheng et al. 2009 and Cheng et al. 2014). Such probes can also determine the location of the interface between different media, which allows them to be configured to monitor changes to the sediment surface continuously. However, the electrical conductivity signal is sensitive to water temperature, salinity and turbidity due to the nature of the electrical conductivity. Normally a careful calibration is therefore required before each test to achieve reliable measurement.

Acoustic signal detecting technology is also frequently used for identifying the water-sand interface. Acoustic sensors dynamically differentiate the material interface by calculating and updating the characteristics of reflected waves that propagate through different materials, namely water and sediment (Morrissey et al., 1985, Hart and Caulfield, 1989, Fisher et al., 2013, Sheppard and Miller, 2006 and Qi and Gao 2014 McGovern et al. 2014). The issues related to air bubbles, water temperature and salinity can be well controlled in laboratory conditions, but the amount of suspended particles and the flow turbidity can cause significant errors for the measurement of the 'true' bed level. 
The Ground-Penetrating Radar (GPR) applied electromagnetic signals at regular time in the frequency range of a $\mathrm{MHz}$ receiver (Olhoeft 1984 and Anderson et al. 2007). Anderson et al. (2007) mentioned that the measurement near structures (such as pile foundations) is less reliable due to reflection from the structure surface and it does not work in clayey environment.

$\mathrm{Yu}$ and $\mathrm{Yu}$ (2009) developed the Time-Domain Reflectometry (TDR) device which uses the changes in the dielectric permittivity constants between materials to determine the depth of scour at a particular location. Fisher et al. (2013) evaluated this TDR sensor and found the sensor is also sensitive to water temperature, salinity and turbidity.

For clear water conditions, lasers are also used widely in laboratory conditions. Zhao et al. (2010) measured scour around subsea caisson models using a point laser to scan the scour profile after draining water out. It was found that the process can be time consuming to achieve a high resolution profile. A line laser can be used to improve the scanning efficiency. Stereo vision is also a laser signal based method to measure three-dimensional scour profile around model structures (Bajlio et al. 2001, Sumer et al. 2013).

When a cyclic pressure is acting on a sandy seabed, the sand undergoes periodic elastic shear deformation and induces cyclic pressure fluctuation in the seabed. The cyclic pressure could be induced by ocean waves or by earthquakes. If the pressure does not dissipate fully before next wave action, a progressive pore pressure build-up will happen in the seabed. When the pressure build-up exceeds a certain value, the pressure will overcome the friction between the soil particles and trigger liquefaction to the seabed. This is potentially a hazard for most of the subsea structures.

Compared with the research on local scour, relatively less research work has been published on seabed liquefaction (Seed and Rahman 1978, and Sumer et al. 1999 etc.). As explained above, the fundamental reason for seabed liquefaction is pore pressure build-up. Naturally most of the physical experiments measure the liquefaction process using pore-pressure transducers (Sumer et al. 1999).

In this work, optical backscatter (OBS) sensors were used for detecting both the local sediment transport around model structures and seabed liquefaction based on the different reflection coefficient when sediment movement happens. It is expected that the sensor will provide a new way for monitoring local scour and seabed liquefaction.

This paper is organized in the following structure. In section 2, the detailed information about the sensor is given. Section 3 describes the testing setup and section 4 presents the test results. Section 5 gives the conclusions.

\section{OPTICAL SENSORS}

In this work, two optical sensors were used for the purpose of detecting/evaluating local scour and soil liquefaction around a model structure. The two sensors included an optical backscatter (OBS) sensors and an Infra-red scanner. The OBS sensors were used to detect the scour development process during the tests and the Infra-red scanner was used to capture the full three-dimensional scour profile at the end of the tests. The detailed information of the two sensors are given below.

\subsection{Optical backscatter sensor}

The OBS sensor used in this work is a type of optical sensor often used as a counter sensor, edge sensor and end sensor. An infrared photodiode is utilized for light signal output while a single phototransistor and a light receiver element are integrated for light detection. The model used in this work has a circular rod shape with diameter of $4 \mathrm{~mm}$ and length of $16.5 \mathrm{~mm}$ (Figure 1 (a)). A picture and the detailed dimensions of the sensor are given in Figure 1 (b). The sensor reading is defined as $R c$, which is a non-dimensional parameter representing the strength of the reflected light. When the sensors are buried in sand, the sand particles around the sensors can reflect the light emitted by the sensor and $\mathrm{Cr}$ value is around 20 25 for the sand used in this work. When the sensor is exposed to water, the reading of the sensors drop dramatically to near zero, due to the low reflection rate of water. Therefore a sharp change of $\mathrm{Cr}$ can be detected when the sensor is fully exposed. This is the principle used for detecting scour level around the model.

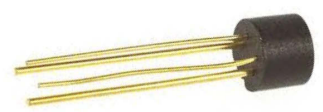

(a)

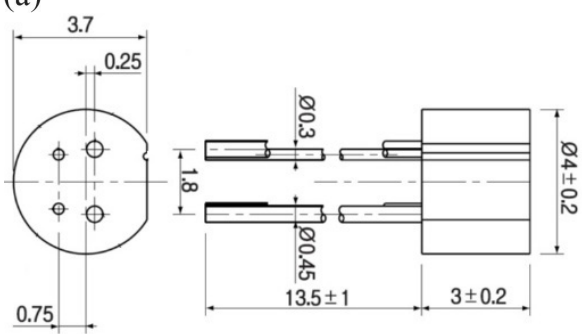

(b)

Figure 1. The OBS sensor. (a) a picture, (b) detailed dimensions of the sensor (unit in: $\mathrm{mm}$ ).

When the sensor is buried in sand, the sensor readings show very small scale fluctuation, but the fluctuation scale increases noticeably when the sand particles move around the sensors, even the sensors still remain buried. This feature is used to detect seabed liquefaction. Moreover, as ambient light interferes with the sensor reading, the tests were conducted under dark environment. 


\subsection{Infra-red scanner}

For local scour tests, the final scour profile of each experiment was scanned using a handheld threedimensional (3D) scanner based on Microsoft Kinect. The 3D scour profile was detected by an infrared (IR) emitter and an IR depth sensor equipped in the scanner. The emitter emits infrared signal beams and the depth sensor reads the IR beams reflected back to the sensor. The reflected signal is converted into depth information measuring the distance between the scour hole and the sensor. The resolution of the resulting $3 \mathrm{D}$ depth image is up to $640 \times 480$ pixels and the frame rate is up to 30 frames per second. The resolution of the infrared camera is determined by the distance between the sensor and the seabed. In this study, the maximum distance between the 3D scanner and the seabed is below $1 \mathrm{~m}$. The precision of the 3D scour profile data is approximately $2 \mathrm{~mm}$. The best scan data can be achieved by draining water out of the test section, but the scanner can scan profiles through a maximum water depth of $0.4 \mathrm{~m}$. An example scanned profile is given in Figure 2 (scan in air).

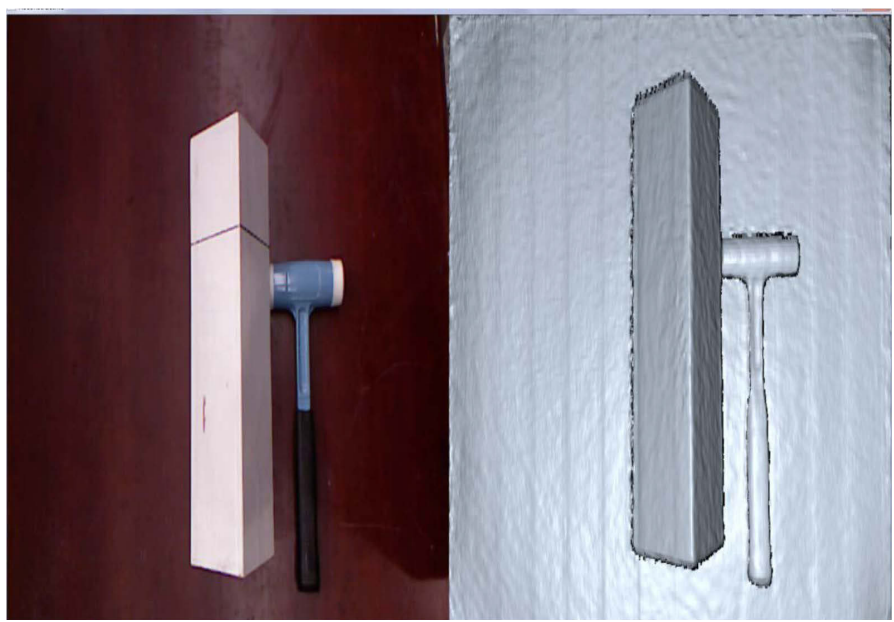

Figure 2. An example of scanned objects using the 3D infra-red scanner.

\section{TESTING SETUP}

In this work, three model tests are presented, which includes a pile scour test, a pipeline scour test and a liquefactions test. Detailed testing setup information is presented below.

\subsection{Testing flume}

The model tests were conducted in a water flume with dimensions of $0.4 \mathrm{~m} \times 0.5 \mathrm{~m} \times 15 \mathrm{~m}$ (width $\times$ depth $\times$ length), and a sand section of $1.15 \mathrm{~m}$ length and $0.3 \mathrm{~m}$ depth (Figure 3). A model seabed built with non-cohesive siliceous sand was used for the scour tests. The particle size distribution of the sand is shown in Figure 4. The sand is a narrowly graded sediment, with the majority of sediments between
0.1-0.4 $\mathrm{mm}$ in size, and the median grain size $\left(d_{50}\right)$ is $0.243 \mathrm{~mm}$. Less than $3 \%$ of the particles have particle size less than $0.1 \mathrm{~mm}$, which indicates the sediment is expected to be non-cohesive. The standard deviation of the sand is $\sigma_{\mathrm{g}}=1.48$. The specific gravity of the sand is $s_{\mathrm{g}}=2.65$.

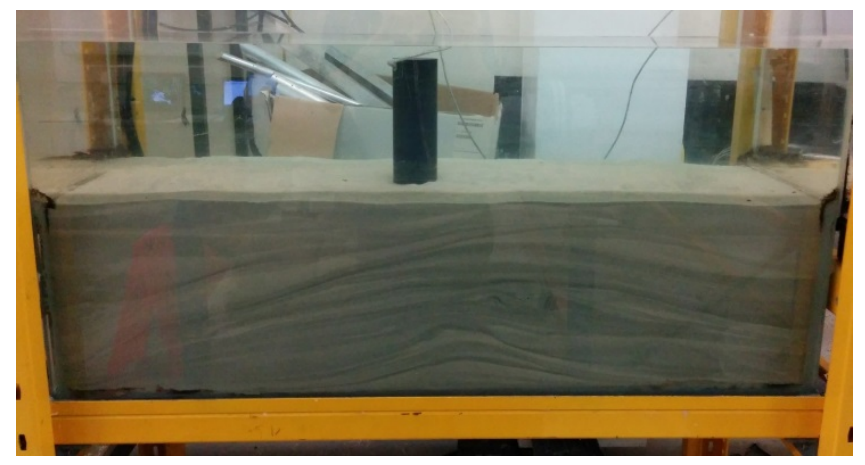

Figure 3. The model setup for the pile scour test.

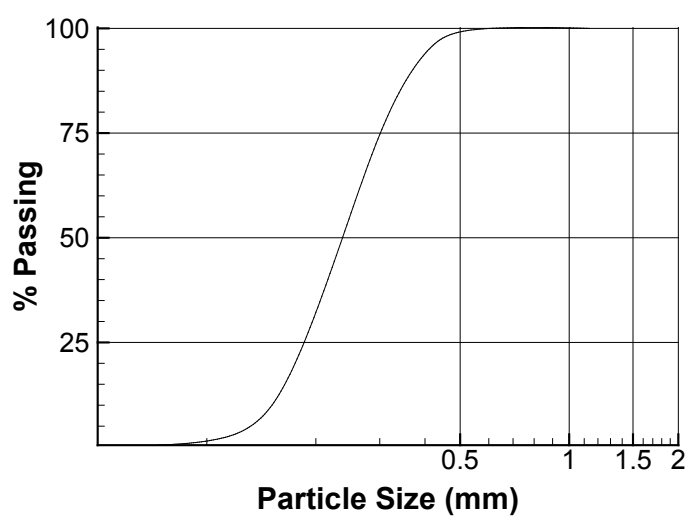

Figure 4. Particle-size distribution of super-fine sand

\subsection{OBS Model}

A $300 \mathrm{~mm}$ long PVC cylinder with diameter $D=70$ $\mathrm{mm}$ was used as a structure model to examine the local scour. 16 OBS sensors were installed in the model along a line parallel to the axis of the cylinder. From one end of the model, the first 6 sensors were $5 \mathrm{~mm}$ apart, the next 9 sensors were positioned $10 \mathrm{~mm}$ apart, and the final sensor was $20 \mathrm{~mm}$ away from the adjacent sensor. A photo of the sensor is given in Figure 5.

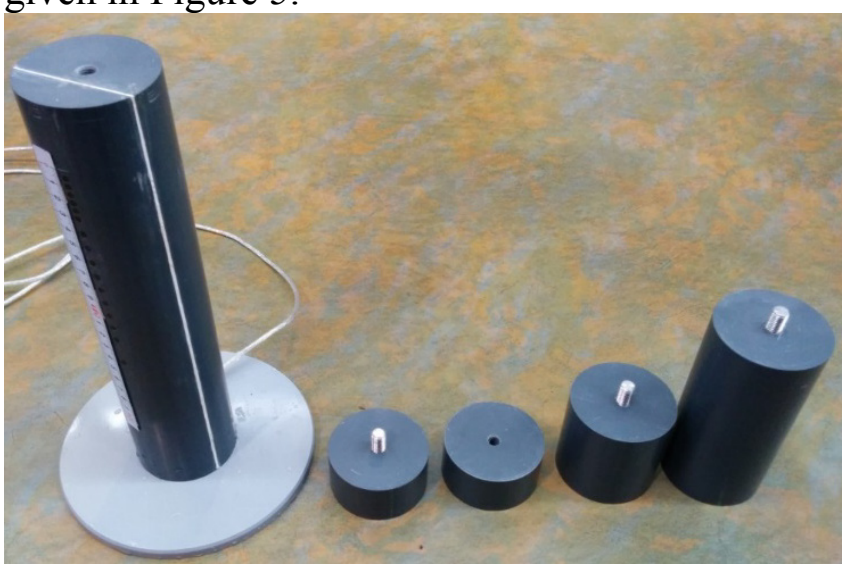

Figure 5. A picture of the OBS model cylinder with extending sections. 
16 channels of data with $10 \mathrm{~Hz}$ sampling rate were recorded during each test and then the scour process was analyzed to investigate the scour depth and scour time scale.

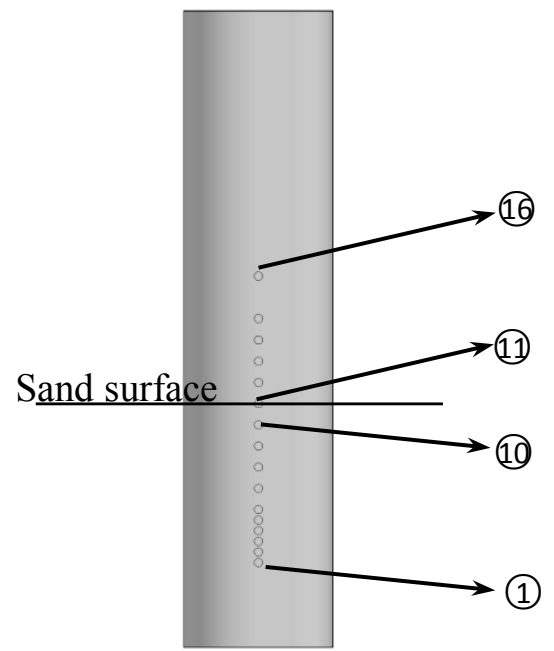

Figure 6. Model setup for the pile scour test (sensor 1 was at the lower end).

\subsection{Testing method}

In this work, three tests were conducted to examine the performance of the OBS sensors, including two local scour tests and one liquefaction test. In the first scour test, the cylinder was buried vertically with an exposed length of 3D. This test was to simulate the scour around a vertical pile. In the second scour test, the cylinder was placed horizontally with $0.2 \mathrm{D}$ embedded. This test was conducted to examine the scour rate along the spanwise direction of a subsea pipeline. Both of the two scour tests were conducted under steady current condition. In the last test, the model was fully buried in the model seabed to examine the response of the OBS sensors to liquefied sand. The liquefaction was induced by applying a jet water supply from the bottom of the model seabed.

Steady current was applied in the two local scour tests. The flow boundary layer profile at the model location was measured before starting the scour test. The measured velocities were fitted to the log profile

$\frac{u(z)}{U_{f}}=\kappa \ln \left(\frac{z}{z_{0}}\right)$

where $u(z)$ is velocity at level $z$ above the bed, $U_{f}$ is friction velocity, $\kappa$ is a constant $(=0.4)$ and $z_{0}$ is the roughness length. Using linear regression, the value of $U_{f}$ and $z_{0}$ were calculated. For pile scour tests, the value of $U_{f}=0.015 \mathrm{~m} / \mathrm{s}$ and $z_{0}=0.038 \mathrm{~mm}$ were calculated for pile scour test. Based on these results the Shields number, given by

$\theta=\frac{U_{f}^{2}}{g(s-1) d_{50}}$ was calculated to be 0.072 . The critical Shields number was calculated according to

$\theta_{c r}=\frac{0.3}{1+1.2 D^{*}}+0.055\left[1-e^{-0.02 D^{*}}\right]$,

where

$D^{*}=\left[g\left(s_{g}-1\right) / v^{2}\right]^{1 / 3} d_{50}$.

The critical shields number $\theta_{c r}$ is 0.042 for this sediment. Therefore the pile scour test was under live bed condition. For the model pipeline scour test, the averaged velocity was $0.39 \mathrm{~m} / \mathrm{s}$ and the corresponding Shields number was $\theta=0.083$.

For the liquefaction test, the OBS model was fully buried in the sand in vertical direction together with a set of pore pressure sensors.

\section{TEST RESULTS.}

\subsection{Pile scour test.}

The scour around a vertical pile is due to the horseshoe vortex from upstream and Karman vortex shedding from downstream. Detailed review about pile scour can be found in Sumer and Fredsøe (2002). The pile test result with the OBS sensors is presented in this section. In this test, the model was installed vertically with sensor 1 to 10 buried in sand and sensor 11 to 16 exposed to water. Sensor S01 was at the lower end of the sensor array. The test duration was about $6000 \mathrm{~s}$, during which sensor 2 to 10 were exposed (Figure 6). Sample readings from the sensors are shown in Figure 7. Before starting the flow, the sensors buried in sand read around 21 to 22 and exposed sensors read around zero. The flow was started at $t=100 \mathrm{~s}$. It can be seen that once the flow started, the reading of Sensor 10 dropped dramatically from $C_{r}=21$ to nearly zero. This means the sensor was exposed due to the sand around the pile being washed away. Figure 7 shows that the buried sensors were exposed one by one from top to bottom. The moment that the reading drops dramatically corresponds to scour reaching the sensor level. Based on this feature, the scour process based on sensor readings is given in Figure 8. The figure comprises 11 data points, in which 9 points were based on the sensors $(2 \sim 10)$. The last data point in the figure was based on the visual measurement after stopping the test. The sensor S01 at the lower end of the model was not exposed during the test. Strong fluctuations in the sensor reading time histories were observed after the sensors were exposed. This is because the sand particles sliding into the scour hole from the upstream slope accumulated around the 
sensor that was just exposed, before being washed further downstream.

It can be seen from Figure 8 that the data points follow the typical features of local scour around a pile. The data points were fitted with the exponential equation proposed by Sumer and Fredsøe (2002),

$s(t) / D=S_{0} / D(1-\exp (-t / T))$,

where $s(t)$ represents the scour depth at time $t, S_{0}$ is the equilibrium scour depth and $T$ is the scour time scale. It can be seen that the data can be fitted reasonably well. The curve fitting results give $S_{0} /$ $D=0.97$, which is in good agreement with the measurement given by Sheppard and Miller (2006) and Zanke et al. (2011). This case demonstrates that the scour process was captured clearly with the OBS sensors. More sensors can be fitted to the model cylinder if a higher resolution is required.

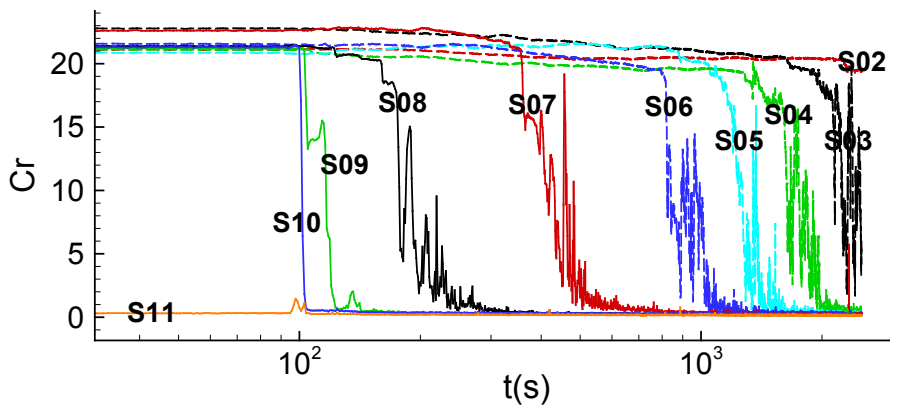

Figure 7. Reading of the OBS sensors for the pile scour test.

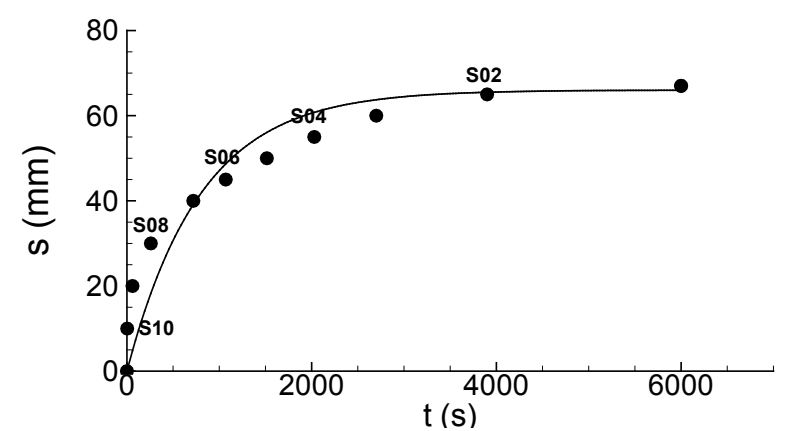

Figure 8 . The scour developing process determined by the OBS sensors.

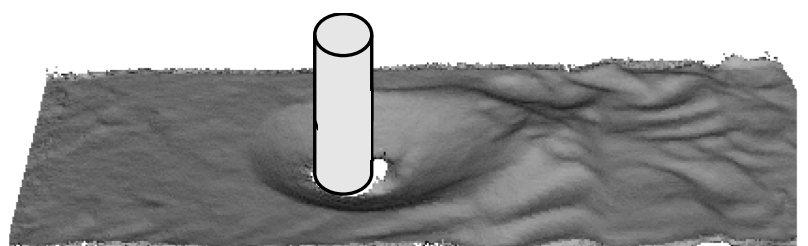

Figure 9. The final three-dimensional scour profile for the pile test.

\subsection{Pipeline scour test}

Scour below a subsea pipeline often happens in a three-dimensional manner. For a partially buried pipeline, onset of tunnel scour can be triggered by piping (Sumer and Fredsøe, 2002) when the pressure gradient below the embedded part exceeds a critical value. Once onset happens, the scour hole will extend vertically and along the spanwise direction of the pipeline (Cheng et al. 2009 and Cheng et al. 2014). It is important to have an accurate prediction about the scour rate in the spanwise direction for subsea pipeline laid on an erodible seabed. It has been known that the conductivity probes, which have been used previously to measure this rate, have limitations as mentioned in the introduction section (see also Fisher et al. 2013). It is expected that the OBS sensor can provide an alternative method to measure the scour rate along the pipeline.

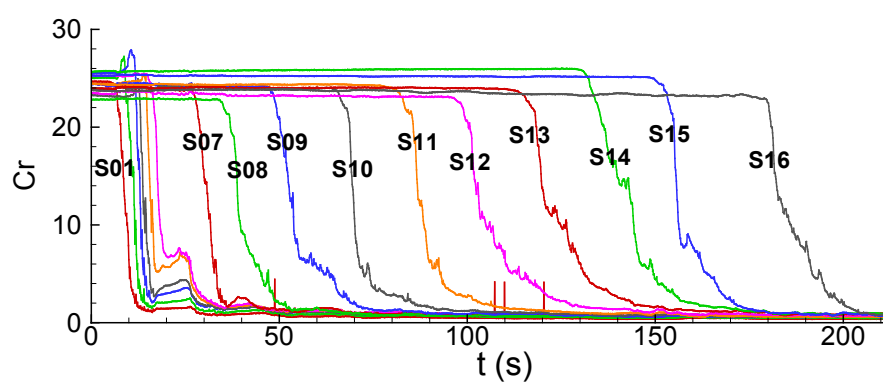

Figure 10. Reading of the OBS sensors for the pipeline scour test.

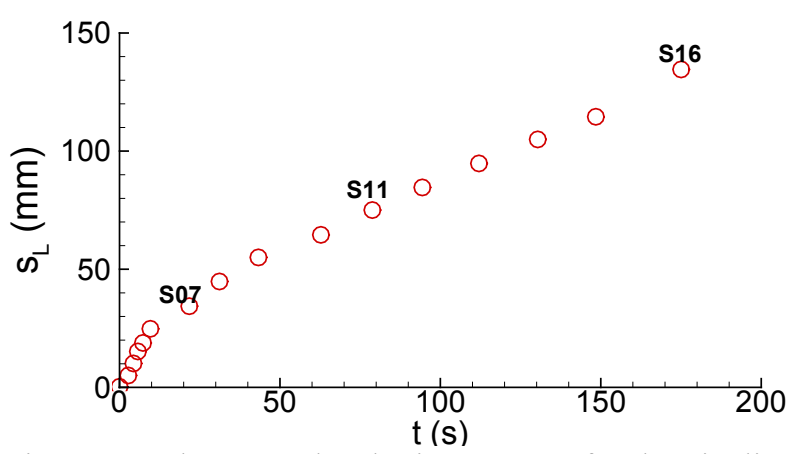

Figure 11. The scour developing process for the pipeline model test determined by the OBS sensors.

Here we report the test results for simulating the three-dimensional scour below a subsea pipeline model using the OBS cylinder. The model was partially buried in the horizontal direction with an initial uniform burial depth of $0.2 \mathrm{D}$. The depth averaged flow velocity was $0.39 \mathrm{~m} / \mathrm{s}$. At the end of the model near sensor S01, the sand under the model cylinder was removed to serve as an initiation point for tunnel scour. After starting the flow, the scour under the pipe developed vertically and also in the spanwise direction. The test was stopped at $300 \mathrm{~s}$ when the scour hole reached the other end of the model cylinder. The OBS sensors cannot measure scour depth under the pipe, but can be used to monitor the scour development rate along the spanwise direction. The working principle is identical to that in the pile scour test. 


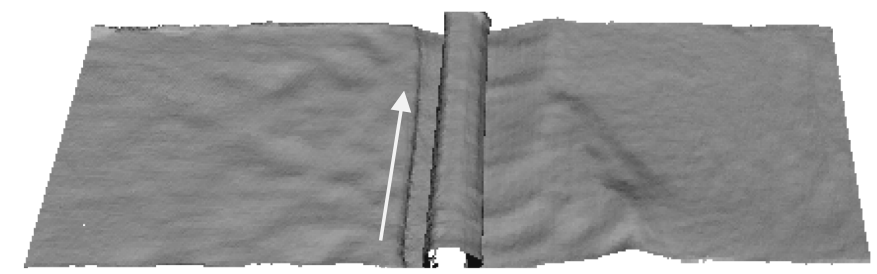

Figure 12. The finial three-dimensional scour profile for the pipeline model test (flow direction was from left to right and the arrow indicates the scour developing direction).

The reading time history of the sensors are plotted in Figure 10. It can be seen that all the 16 sensors experienced a very similar trend, starting from sensor S01, and then the other sensors followed one by one. This demonstrated the scour propagated along the spanwise direction. The scour development process is extracted based on the sensor readings and plotted in Figure 11. It can be seen that the scour developed linearly but at two different rates. For the first 6 sensors, the scour rate was $2.32 \mathrm{~mm} / \mathrm{s}$ and then the rest was $0.66 \mathrm{~mm} / \mathrm{s}$. The ratio between the two rates was $2.32 / 0.66=3.52$, which is in an excellent agreement with the conclusion given be Cheng et al. (2009). The final scour profile is given in Figure 12. This case demonstrated that the OBS sensors are suitable for detecting the spanwise scour rate under a subsea pipeline model.

\subsection{Liquefaction test}

The sand used in this work is relatively coarse. There was no obvious pressure build-up when waves were generated in the flume. Therefore liquefaction was generated by applying a jet water supply at the bottom of the sand bed. The test setup is given in Figure 13. The model cylinder was buried vertically in the sand bed and the top of the cylinder was 50 $\mathrm{mm}$ below the sand surface. A pore-pressure sensor tower with four sensors was also buried vertically in the sand at a distance $100 \mathrm{~mm}$ away from the OBS cylinder. The four pore pressure sensors were named P01 to P04, with P01 at the lower end. A water supply capable of providing a vertical jet of water was buried under the sand bed in between the OBS cylinder and the pore pressure tower. The water in the flume was kept still. Both the OBS model and the pore pressure tower were secured at its location to make sure the models do not move during seabed liquefaction.

To avoid excessive scour induced by the jet, the water supply was only switched on for 15 seconds for the tests. The response of the OBS sensors and the pressure sensors are examined in Figure 14 and Figure 15. Figure 14 shows the pore pressure response during the test. It can be seen that the P01 sensor experienced a dramatic increase with a peak value of $4 \mathrm{kPa}$ during the test and then gradually dissipated. The response of P02 and P03 are very similar to that of P01, but with much lower peak values.
This is because the two sensors were further away from the jet water supply. S04 showed no response to the test due to its location being beyond the range that was affected by the jet water.

The reading of the OBS sensors were examined as plotted in Figure 15. The reading of 6 sensors are plotted (note, each sensor reading is plotted with an offset of 20 to compare the curves clearly). It can be seen that before starting the test, the sensors were almost reading constant values. After the jet flow was applied from the bottom of the test section, there is also an obvious increase in the S01 reading with strong fluctuation. After about $t=34 \mathrm{~s}$, the reading dropped back to a constant value. The curve for S04 and S07 show very similar features but with an obvious phase difference. For sensors above S09, the fluctuation of the reading became very weak. This feature indicated that the soil liquefaction happened during the test. This is because the sensor reading remains a constant value when nothing moves around it. By comparing Figure 14 and Figure 15, it can be found that strong soil particle movement did not happen when the pore pressure reached a peak value but happened during the dissipation period. It also can be found the particles settled before the pore pressure fully dissipated.

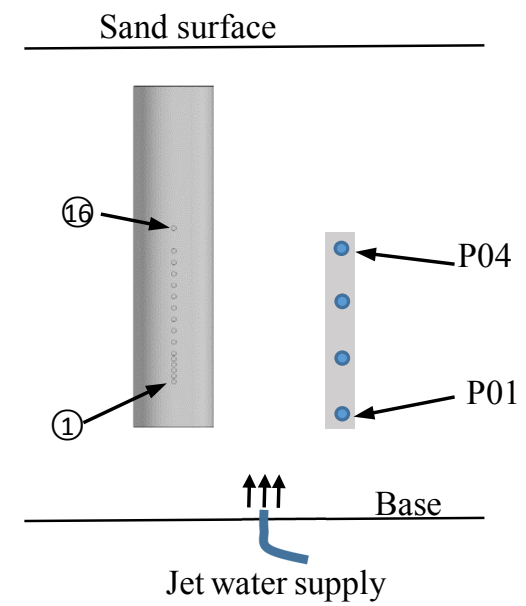

Figure 13. The testing setup for the liquefaction test.

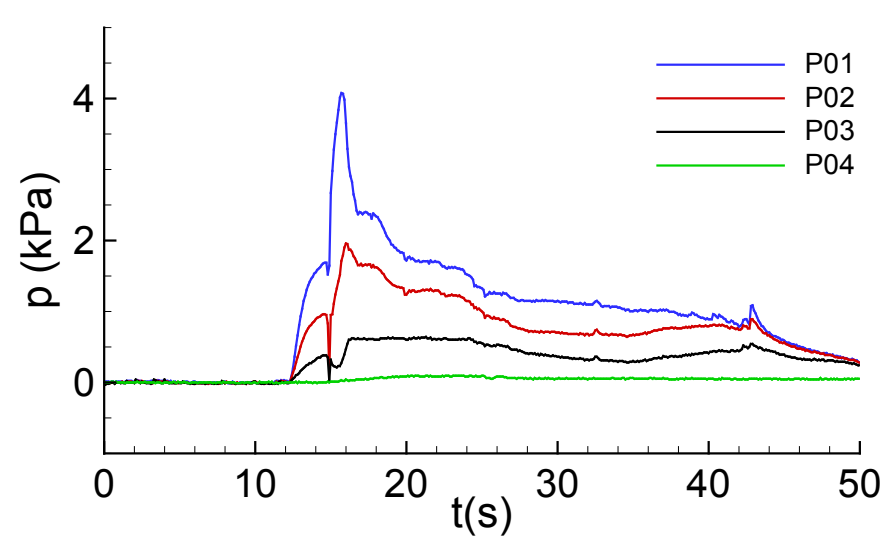

Figure 14 . The pore pressure time history during the liquefaction test. 


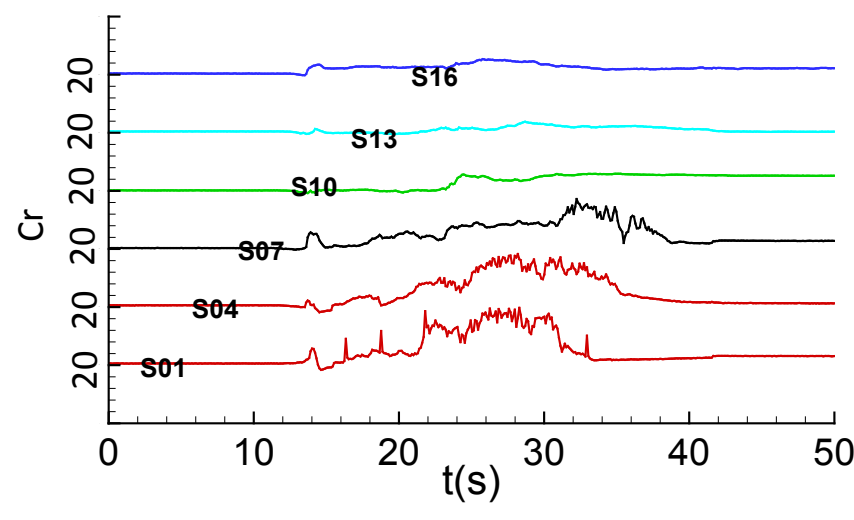

Figure 15 . The OBS reading time history during the liquefaction test.

\section{CONCLUSION}

In this work, a series of physical experiments were carried out to examine the performance of the OBS sensors for detecting local scour and liquefaction around structure models.

The OBS sensors are sensitive to the surrounding environment. When it is covered by sand, the $\mathrm{Cr}$ value is often around 20, but $\mathrm{Cr}$ drops to near zero when the sensor is exposed to clear water. Based on this feature, the local scour process around pile models and pipeline models can be monitored using the OBS sensors. The test results agree well with published data. This demonstrated that the OBS sensors can serve as a new technology to measure local scour in laboratories.

The OBS sensors are also sensitive to the sand particle movement even when the sensors are fully buried. Based on this feature, the OBS sensors were used to examine the liquefaction under the sand bed. It was found the sand movement happened during the pore pressure dissipation period and the liquefied sand settles before the pore pressure fully dissipated.

\section{ACKNOWLEDGEMENT}

The authors would like to acknowledge the support from Australia Research Council through ARC Discovery Projects (DE150100428 and DP150104644) and the Laboratory Open Fund from SLCOE, DUT. Mr. Philip Hortin is acknowledged for fabricating the model cylinder.

\section{REFERENCE}

Anderson, N.L., Ismael A. and Thitimakorn. 2007. GroundPenetrating Radar: A Tool for Monitoring Bridge Scour. Environmental \& Engineering Geoscience. 13 (1), 1-10.
Ballio, F, Radice A, and Day, S. 2010. Temporal Scale for Live -Bed Scour at Abutments. Journal of Hydraulic Engineering. 136, 395-402.

Breusers, H.N.C., Nicollet, G., Shen, H.W., 1977. Local scour around cylindrical piers. Journal Hydraulic Research 15 (3), 211-252.

Briaud, J.L., Ting, F., Chen, H.C. Gudavalli, R., Perugu, S. Wei, G. 1999. SRICOS: prediction of scour rate in cohesive soils at bridge piers. Journal of Geotechnical and Geoenvironmental Engineering, 125 (4), 237-246.

Cheng, L., Yeow, K, Zang, Z., and Teng, B. 2009. Threedimensional scour below offshore pipelines in steady currents. Coastal Engineering. 56, 577-590.

Cheng, L., Yeow, K, Zang, Z., and Li, F. 2014. Threedimensional scour below offshore pipelines under waves and combined waves and current. Coastal Engineering. 83, 137-149.

De Falco, F. and Mele, R. 2002. The monitoring of bridges for scour by sonar and sedimetri. NDT\&E International, 35 (2), 117-123.

Downing, J.P., Sternberg, R.W. and Lister, C.R.B., 1981. New Instrument for the Investigation of Sediment Suspension Processes in the Shallow Marine Environment. Marine Geology, 42, p. 19-34.

Fisher, M., Chowdhury, M.N., Khan, A.A., Atamturktur, S. 2013. An evaluation of scour measurement devices. Flow Measurement and Instrumentation, 33, 55-67

Hart, E.D. and Caulfield, D.D., 1989. Acoustic determination of bridge scour. In Proceedings of the Bridge Scour Symposium: McLean, Virginia, Federal Highway Administration Report FHWA-RD-90-035 (pp. 130-146).

Hiroshi S. and Mikio A. 1983. Vortex shedding from a rectangular prism and a circular cylinder placed vertically in a turbulent boundary layer. Journal of Fluid Mechanics. 126, 147-165.

Hoffmans, G.J.C.M., Verheij, H.J., 1997. Scour Manual. A. A. Balkema, Rotterdam

Kawamura, T, Hiwada, M, Hibino, T, Mabuchi, I and Kumada, M (1984) "Flow around a finite circular cylinder on a flat plate", Bull. JSME 27 (232), 2142-2159.

McGovern, D.J., Ilic, S., Folkard, A.M., McLelland, S.J. and Murphy, B.J., 2014. Time development of scour around a cylinder in simulated tidal currents. Journal of Hydraulic Engineering, 140(6), p.04014014.

Morrissey, D. J.; Haeni, F. P.; and Tepper, D. H., 1985, Continuous seismic-reflection profiling of glacial-drift deposits on the Saco River, Maine and New Hampshire: Proceedings, 2nd National Water Well Association Annual Eastern Regional Groundwater Conference, Portland,. 277-296.

Kawamura, T, Hiwada, M, Hibino, T, Mabuchi, I and Kumada, M (1984) "Flow around a finite circular cylinder on a flat plate”, Bull. JSME 27 (232), 2142-2159.

Krajnović, S (2011). "Flow around a tall finite cylinder explored by large eddy simulation," Journal of Fluid Mechanics. 676, 294-317.

Olhoeft, G. R., 1984, Applications and limitations of ground penetrating radar: Society of Exploration Geophysicists 54th Annual International Meeting, Atlanta, Georgia: Soci- 
ety of Exploratoin Geophysicists, Houston, TX, pp. 147148.

Qi, W. and Gao, F., 2014. Equilibrium scour depth at offshore monopile foundation in combined waves and current. Science China Technological Sciences, 57(5), pp.1030-1039.

Richardson, E.V., Davies, S.R., 1995. Evaluating scour at bridges, US Department of Transportation, HEC 18, FHWA-IP-90-017, 3rd edn.

Seed, H.B., Rahman, M.S., 1978. Wave-induced pore pressure in relation to ocean floor stability of cohesionless soil. Mar. Geotechnol. 3 (2), 123-150

Simpson R.L. 2001. Junction flows. Annual Review of Fluid Mechanics. 33, 415-443.

Sheppard, D. and Miller, M. Jr., 2006. Live-Bed Local Pier Scour Experiments. Journal of Hydraulic Engineering. 7, 635-642.,

Sheppard, D.M., Odeh, M., Glasser, T., 2004. Large scale clear-water local pier scour experiments. Journal of Hydraulic Engineering, ASCE 130 (10), 957-963.

Soulsby, R., 1997. Dynamics of Marine Sands. Tomas Telford Ltd. 249 pp.

Sumer, B.M., Fredsøe, J., Christensen, S. and Lind, M.T., 1999. Sinking/floatation of pipelines and other objects in liquefied soil under waves. Coastal Engineering, 38(2), pp.53-90.

Sumer, B.M., and Fredsøe, J., 2002. The Mechanics of Scour in the Marine Environment.World Scientific, Singapore. 536 pp.

Sumer, B.M., Petersen, T.U., Locatelli, L., Fredsøe, J., Musumeci, R.E., Foti, E. 2013. Backfilling of a scour hole around a pile in waves and current. Journal of Waterway, Port, Coastal and Ocean Engineering. 139, (1), 9-23.

Whitehouse, R., 1998. Scour at Marine Structures. Thomas Telford.

$\mathrm{Yu}$ X, and Yu, X. 2009. Time domain reflectometry automatic bridge scour measurement system: principles and potentials. Structural Health Monitoring, 8. 463-476

Zanke, U.C.E. Hsu, T. W., Roland, A., Link, O. and Diab, R. 2011. Equilibrium scour depths around pile in noncohesive sediments under currents and waves, Coastal Engineering 58(2011) 986-991.

Zhao, M, Cheng, L and Zang, Z. 2010. Experimental and numerical investigation of local scour around a submerged vertical circular cylinder in steady currents, Coastal Engineering, 57, 709-721 